\title{
Assessment of artificial and natural sweeteners present in packaged non- alcoholic beverages (NABs) sold on the Singapore market
}

Rebecca Tan ${ }^{1 *}$, Sharon Chew ${ }^{1}$, Xenia Cleanthous ${ }^{2}$, Kimberley Anastasiou², Paige G. Brooker ${ }^{2}$, Theresa Pham ${ }^{3}$ and Benjamin P. C. Smith ${ }^{1,4}$

\begin{abstract}
Background: New Nutri-Grade labelling, aimed at reducing Singaporeans' sugar consumption will be implemented for all pre-packaged non-alcoholic beverages (NABs) sold in retail outlets from end 2021 onwards. It is expected such labelling will have a major impact on sugar content of beverages, as well as the replacement of sugar with non-caloric alternatives.

Methods: This study used product label data obtained from in-store surveys to investigate sugar and sweetener composition of NABs present on the Singapore market. Using this data we calculated products prospective Nutri-Grade classification in order to compare the current market composition with relation to sugar and/or sweetener use.

Results: Over half of the NABs on market were sweetened with sugar (59\%) and were associated with less healthy Nutri-Grades of ' $C$ ' and 'D'. The use of natural sweeteners; Stevia and Monk fruit, remains low (6\%).

Conclusion: With continuous efforts by the government in promoting public health nutrition, it is expected that there will be a greater usage of sugar substitutes among NABs in response to the upcoming implementation of Nutri-Grade and ever-fluctuating consumers' demands. The data collected in this study provide a point estimate (July-September 2020) on market composition and use of both sugar and artificial sweeteners in beverages prior to integration of the mandatory labelling requirements.
\end{abstract}

Keywords: Market survey, Non-alcoholic beverages, Singapore, Sugar, Sugar substitutes

\section{Background}

In recent years, the health consequences of regular consumption of sugar-sweetened beverages (SSBs) have gathered a considerable amount of attention [1-3]. Many studies conducted have documented that the consumption of dietary sugar present in SSBs is directly

\footnotetext{
* Correspondence: rmp3523@hotmail.com

${ }^{1}$ Singapore Institute of Food and Biotechnology Innovation \& Innovations in Food \& Chemical Safety Programme, Agency for Science, Technology and Research, Singapore 138671, Singapore

Full list of author information is available at the end of the article
}

linked to the increased prevalence of obesity in the population [2-7]. Furthermore, this is positively correlated with increases in the development of metabolic diseases such as type 2 diabetes mellitus (T2DM) $[1-4,8$, 9]. SSBs are acknowledged to be one of the main causes of T2DM as it contains the single largest source of sugar in the diet $[6,9]$.

According to Singapore's Health Promotion Board (HPB), the average sugar level for medium- and highersugar SSBs per $250 \mathrm{~mL}$ serve in Singapore is around $25 \mathrm{~g}$ [10]. Beverages containing this amount of sugar represented

(C) The Author(s). 2021, corrected publication 2021. Open Access This article is licensed under a Creative Commons Attribution 4.0 International License, which permits use, sharing, adaptation, distribution and reproduction in any medium or format, as long as you give appropriate credit to the original author(s) and the source, provide a link to the Creative Commons licence, and indicate if changes were made. The images or other third party material in this article are included in the article's Creative Commons licence, unless indicated otherwise in a credit line to the material. If material is not included in the article's Creative Commons licence and your intended use is not permitted by statutory regulation or exceeds the permitted use, you will need to obtain permission directly from the copyright holder. To view a copy of this licence, visit http://creativecommons.org/ licenses/by/4.0/. The Creative Commons Public Domain Dedication waiver (http://creativecommons.org/publicdomain/zero/1. 0/) applies to the data made available in this article, unless otherwise stated in a credit line to the data. 
approximately $50 \%$ of the total sales of pre-packaged SSBs in Singapore in 2017 [10]. As part of the 'War on Diabetes', the Government will be implementing mandatory front-of-pack nutrition labels, the Nutri-Grade system (Fig. 1), to assist consumers in discerning between healthier and less healthy product options [11, 12]. Such labelling will take effect by the end of 2021 for all pre-packaged and store-made non-alcoholic beverages (NABs) sold in the Singapore market [10].

Under the Nutri-Grade labelling, all NABs will be assigned a summary grade of A-D, based on a set of nutrition thresholds that includes both free sugar, and saturated fat values (Fig. 2) [10]. In addition to the assigned grades, the respective percentages of sugar contained in beverages will be displayed (Fig. 1) [11]. Although such labels are mandatory to be displayed among beverages that fall under grades $C$ and $D$, it is voluntary for beverages that achieve Grades A and B [10]. It is expected that most beverages labelled with Grades A and B will also qualify for the Healthier Choice Symbol (HCS) label, a classification also awarded by the HPB and is identified by a red pyramid label as displayed in Fig. 2 [10]. HCS requirements, based on nutrient cut-offs set by the HPB, including sugar, saturated fat, trans fat, sodium, calcium and wholegrains, vary for different food groups. Food products are awarded and can display the HCS if they meet those particular nutritional standards [13].

The above labelling requirements are currently restricted to packaged products and are not required for beverages prepared at cafés, restaurants and takeout outlets like Starbucks ${ }^{\mathrm{Tn}}$ or Boost Juice ${ }^{\mathrm{Tx}}$. Although storemade drinks such as sugarcane juices, bubble teas and milkshakes, contribute to the overall sugar intake of Singaporeans, menu labelling requirements currently do not exist in Singapore [14]. Up until now, the Singapore government has relied predominantly on public education and awareness to drive behavioural change to reduce sugar intake [15]. The movement towards labelling packaged products is a first step towards managing intake through regulation which can be linked to import compliance and taxation control.

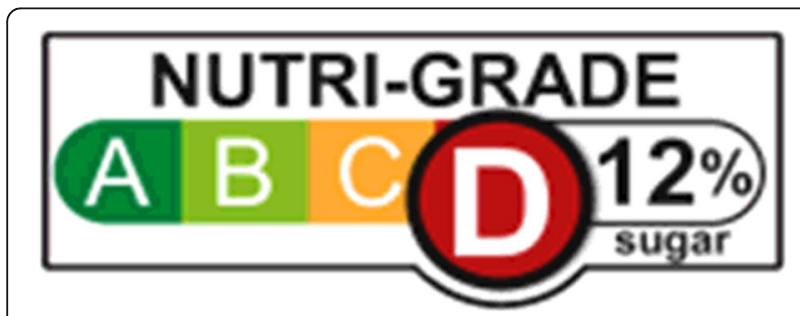

Fig. 1 Nutri-Grade Label [10]
With the implementation of Nutri-Grade, retailers in Singapore are looking towards stocking healthier choices and there is pressure on manufacturers to reformulate beverage formulations. Fully or partially utilizing sugar substitute(s) is part of the approach to meet this goal $[16,17]$. Table 1 provides a summary of the available sugar substitutes in the market, categorized into its respective classes based on nomenclature; caloric contribution and source of origin $[18,19]$.

Evidence investigating the health effects of consuming beverages containing sugar substitute(s) is conflicting and inconclusive $[16,17,24-28]$. This is in part due to a lack of solid knowledge of the product compositions on market in relation to the proportion of sugar substitutes and their contribution to the diet. Some studies have shown that regular consumption of artificially sweetened beverages was associated with increased health risks, including obesity, cardiovascular diseases, and metabolic syndrome [24-26]. Meanwhile, other studies indicated that regular consumption of artificially sweetened beverages had little to no effect on weight gain and even promoted weight loss [27-30].

Due to the differences between studies, such as study duration and design, it is difficult to ascertain the strength and direction of the relationship between the consumption of artificially and/or naturally sweetened beverages and cardiometabolic health over prolonged periods of time and how this compares with sugar [31]. Despite differences in research outcomes about the effects of artificially and/or naturally sweetened beverages on public health, replacing free sugars with sugar substitutes will undoubtedly reduce the total dietary energy intake [28-30] and increased use in the use of sweeteners in products marketed in Singapore is an expected outcome of the implementation of the Nutri-Grade system. Furthermore, with the growing popularity of purchasing clean label and natural products; where the term 'clean labels' is commonly used to describe products lacking artificial flavours, colours, and preservatives, whose ingredient lists are simple with no unpronounceable or 'chemical sounding' additives, the promotion and/or usage of natural and organic sweeteners is predicted to rise [32, 33].

The objective of this study was to obtain baseline data, and position ourselves to monitor future product trends in sugar and sweetener use in non-alcoholic beverages. This study uses package labelling data obtained from instore surveys to investigate sugar and sweetener composition of NABs present on the Singapore market, as well as assess their future Nutri-Grade classification. The data collected in this study provide a point estimate (July-September 2020) on market composition and use of both sugar and artificial sweeteners in beverages prior to integration of the mandatory labelling requirements. 


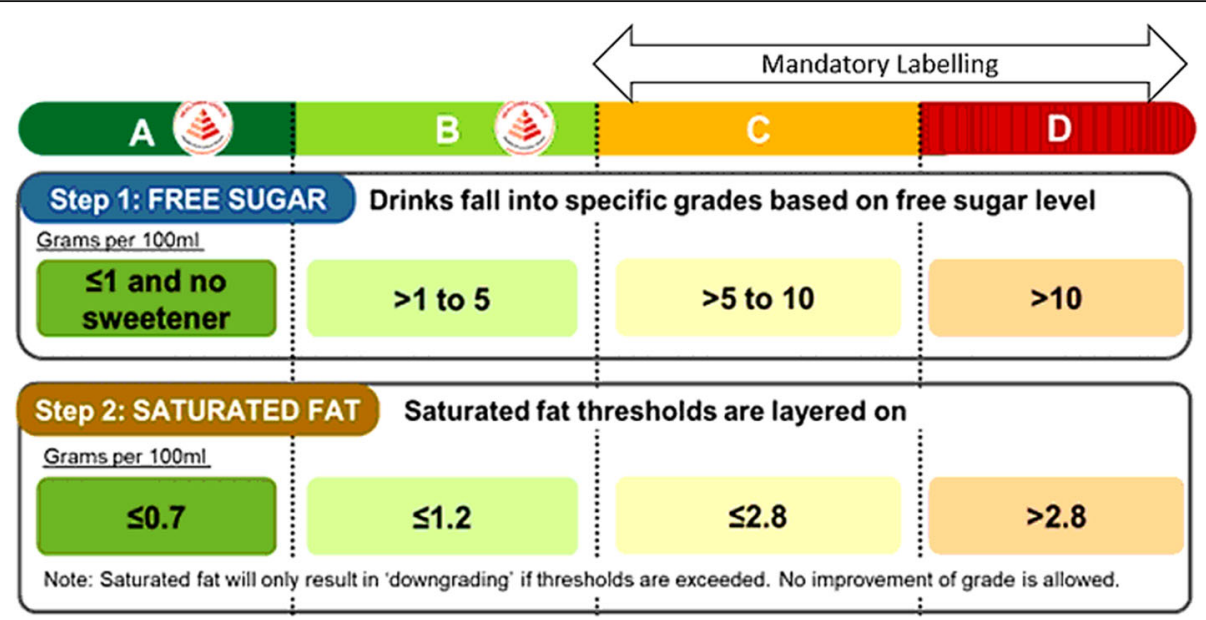

Fig. 2 Nutri-Grade Grading System [10]

\section{Methods}

\section{Data source}

All relevant information on the beverages packaging such like nutritional information panel (NIP), ingredients list and various product descriptor information (e.g., health and nutrition claims, country of manufacture and origin, products that needed to be reconstituted with water or milk before consumption) was collected physically in stores using FoodTrack ${ }^{\text {TM }}$, an Australian food-based composition data collection platform and database technology [34]. Trained personnel visited a total of 12 store locations in Singapore across the four major retail supermarkets: Cold Storage, Giant, NTUC FairPrice and Sheng Siong, and two major convenience stores: 7-Eleven and Cheers after obtaining permission from the respective store managers. Based on an assessment of market share and product listings, it was estimated that these stores covered greater than $90 \%$ of the beverages sold on the Singapore market. On-package information on all beverages positioned in all areas/sections of supermarkets and convenience stores that are categorised as NABs were collected. Data acquisition occurred between July and September 2020.

\section{Study sample}

In this study, NABs were grouped into twelve subcategories based on their ingredient and nutrient compositions. This grouping was based around Australian categories of Sugar-Sweetened Beverages or SSBs in order to align with the current FoodTrack ${ }^{\mathrm{Tm}}$ database categorisation system. Sub-categories included: (1) Asian/ Asian-style drinks; (2) carbonates; (3) coconut water; (4) cordials, syrups, concentrates; (5) energy drinks; (6) flavoured drinks; (7) kombucha; (8) "milk-based/iced

Table 1 Classification and Types of Sugar Substitutes Available in products sold in Singapore [18-23]

\begin{tabular}{|c|c|c|}
\hline Classification of Sugar Substitutes & Types of Sugar Substitute(s) Available & $\begin{array}{l}\text { Sweetness Intensity relative to } \\
\text { Table Sugar }\end{array}$ \\
\hline Caloric/Low-caloric Artificial Sweeteners & Aspartame & 200 times sweeter \\
\hline \multirow[t]{2}{*}{ Natural Sweeteners } & Steviol Glycosides & 200-400 times sweeter \\
\hline & Monk Fruit Extract & 100-250 times sweeter \\
\hline \multirow[t]{6}{*}{ Sugar Alcohols (Sweetness Intensity of Sucrose valued at 1.0) } & & Sweetness Intensity relative to Sucrose: \\
\hline & Erythritol & 0.812 \\
\hline & Lactitol & 0.4 \\
\hline & Maltitol & 0.9 \\
\hline & Sorbitol & 0.6 \\
\hline & Xylitol & 1.0 \\
\hline \multirow[t]{3}{*}{ Zero-Calorie Artificial Sweeteners } & Acesulfame Potassium (Acesulfame-K) & 200 times sweeter \\
\hline & Saccharin & 200-700 times sweeter \\
\hline & Sucralose & 600 times sweeter \\
\hline
\end{tabular}


coffees; (9) "milk-based/iced teas; (10) ready-to-drink (RTD) vinegars; (11) sports/isotonic drinks; and (12) vitamin drinks (see Appendix). Products excluded from data collection and analysis included drinking yoghurt, flavoured milk and milk alternatives, juices (fruits and vegetables), plain bottled water, and milk-based beverages ("milk-based iced coffees and teas where milk was added as an ingredient, not as the basis of the product/ characterising ingredient). Although these excluded beverages may contain added sugar, these products are not categorised as NABs/SSBs in FoodTrack ${ }^{\mathrm{ma}}$ and consequently have not been included in the analysis for this paper.

\section{Data collection}

Photographs of the entire beverage packaging were captured, and relevant qualitative and quantitative information was manually transcribed and entered into the FoodTrack ${ }^{\text {Ti }}$ App for each beverage sampled before being uploaded into a remote database. The following fields of information were extracted: ingredients list, instructions usage, HCS logos and respective claims) NIP values, serving size and net weight/volume. All values and calculations reported on the NIP were normalised to per $100 \mathrm{~g}$ or per $100 \mathrm{~mL}$.

All beverages considered NABs/SSBs, based on our category inclusion criteria, were sampled in each store visited. To ensure no products were missed, collectors were instructed to thoroughly check all aisles in each store, not only those aisles where beverages were primarily sold. The thoroughness of sample collection was verified by repeat visits using different collectors.

\section{Data analysis}

Data was analysed using Microsoft Excel ${ }^{\mathrm{Tm}}$ and Excel Stats $^{\mathrm{Tm}}$ tools (Microsoft Office 2012 - Version 16.0.13530.20368). Beverages were classified according to their sub-categories listed in the inclusion criteria and different parameters were applied to compare the results, including determining the average energy, carbohydrate, sugar and saturated fat contents across subcategories, identifying the types and sum of primary taglines labelled on beverages that provide further product differentiation based on the amount of added sugar content, and comparing the types of sugar and sugar substitutes used across all beverages. Based on the types of sugar and/or sugar substitutes used, each beverage was classified according to one of its pre-defined subcategories; unsweetened, intensely sweetened, calorically sweetened and both calorically and intensely sweetened beverages (where 'calorically sweetened' refers to all beverages that still use sugar in their formulations, regardless of whether or not they use additional artificial sweeteners) [35]. The number of sugar substitutes used in each beverage was tabulated and categorised based on Table 1 [18-22].

Descriptive statistics were presented (mean, standard deviation, ranges, and percentages) for the distinct categories and data points, and subsequently combined for overall analysis across the twelve overarching beverage sub-categories. Nutrient (g) data were rounded to one decimal place, and energy $(\mathrm{kJ})$ data were rounded to the nearest whole number.

\section{Nutri-grade assessment}

Based on the NIP values, beverages were further recategorised into their respective nutrient summary labels in accordance with the Nutri-Grade Grading System guidelines in Fig. 2 [10]. The proportion of beverages' nutritional contents that met the various nutrient claims and summary grades of A to D were summarised and presented as percentages. The average total sugar content was also expressed as a percentage of the total beverage volume.

\section{Results}

In total, $883 \mathrm{NABs}$ were collected and assessed in this study. Thirty-five beverages were excluded from the NIP and Nutri-Grade data analyses as their product labels did not carry any nutritional data and thus the presence or absence of sugars and/or sweeteners could not be ascertained. The absence of such data is not surprising, as under the Singapore food legislation, NIPs are only required for pre-packed foods that carry nutrition and health claims, edible fats and oils, and special purpose food. Most products nonetheless contained NIPs, as evidenced by our data, which is likely more so a reflection of other country's labelling requirements due to the high number of imported products entering Singapore. Of the remaining 848 beverages assessed, on average, vitamin drinks contained the highest sugar content of $22.5 \mathrm{~g}$ per $100 \mathrm{~mL} / \mathrm{g}$ across all sub-categories. This was also reflected in their corresponding high energy $(390 \mathrm{~kJ}$, $93 \mathrm{kCal})$ and total carbohydrate values $(23.4 \mathrm{~g})$. Conversely, the saturated fat content of beverages ranged from 0.0 to $0.7 \mathrm{~g}$ as it was observed that saturated fat contents were mainly influenced by the presence of animal-based ingredients such as milk and milk derivates in several tea and coffee beverages. NABs with the highest saturated fat contents $(0.7 \mathrm{~g}$ per $100 \mathrm{~mL} / \mathrm{g})$ still fell within the lowest threshold (Grade A) for saturated fat limits, therefore, all NABs were graded based on their sugar content. Their grades remained unchanged after taking their respective saturated fat contents into account (Table 2).

Majority of NABs collected fall under Grade C $(n=$ $391,46 \%)$ of the Nutri-Grade, and more than half $(n=506,60 \%)$ of the beverages sold on the market 
Table 2 Nutritional Information of Non-Alcoholic Beverages Across Sub-Category per $100 \mathrm{~mL} / \mathrm{g}(n=848)$

\begin{tabular}{llllll}
\hline & $\mathbf{n}$ & Mean (SD) & & & \\
\cline { 3 - 6 } & & Energy (kJ/kCal) & Carbohydrates (g) & Sugar (g) & Saturated Fat (g) \\
\hline Asian/Asian-style Drinks & 118 & $125 / 30(44)$ & $7.2(2.2)$ & $6.8(2.1)$ & $0.1(0.2)$ \\
Carbonates & 219 & $109 / 26(79)$ & $6.3(4.0)$ & $6.0(3.9)$ & $0.2(0.4)$ \\
Coconut Water & 36 & $94 / 22(24)$ & $5.3(0.8)$ & $4.5(0.8)$ & $0.1(0.4)$ \\
Cordials, Syrups, Concentrates & 33 & $194 / 46(210)$ & $11.3(12.4)$ & $11.1(12.8)$ & $0.0(0.0)$ \\
Energy Drinks & 30 & $164 / 39(109)$ & $9.2(6.9)$ & $7.3(6.7)$ & $0.0(0.0)$ \\
Flavoured Drinks & 40 & $177 / 42(52)$ & $10.2(3.0)$ & $9.0(3.0)$ & $0.2(0.4)$ \\
Kombucha & 18 & $61 / 15(22)$ & $3.6(1.5)$ & $3.0(1.0)$ & $0.1(0.2)$ \\
Milk Based/Iced Coffees & 6 & $199 / 47(29)$ & $8.5(1.2)$ & $6.7(1.2)$ & $0.7(0.2)$ \\
Milk Based/lced Teas & 242 & $155 / 37(303)$ & $7.8(12.4)$ & $5.1(3.4)$ & $0.1(0.3)$ \\
RTD Vinegars & 41 & $374 / 89(318)$ & $21.8(19.1)$ & $19.6(17.2)$ & $0.0(0.0)$ \\
Sports/Isotonic Drinks & 54 & $119 / 28(214)$ & $7.0(12.4)$ & $6.8(11.9)$ & $0.0(0.0)$ \\
Vitamin Drinks & 11 & $390(582)$ & $23.4(35.3)$ & $22.5(33.8)$ & $0.0(0.0)$ \\
Overall & 848 & $149(215)$ & $8.3(10.6)$ & $6.9(7.9)$ & $0.1(0.3)$ \\
\hline
\end{tabular}

fall into the unhealthy bands either Grades C or D (Fig. 3). These beverages would be required to adopt the mandatory labelling requirement if the NutriGrade policy was implemented. The average sugar content across all NABs is $6.9 \mathrm{~g}$ per $100 \mathrm{~mL} / \mathrm{g}$ (average range of 3.0 to $22.5 \mathrm{~g}$ ) and would be predominantly assigned to a yellow label; Grade C (Table 3).

Nearly half $(41 \%)$ of the NABs were compliant with the national nutritional guidelines and were thus eligible for the display of various comparative HCS logos and their accompanying taglines (Table 4). The HCS logo was absent on product labels of four out of 12 beverage sub-categories (i.e., energy drinks, kombucha, RTD vinegars and cordials, syrups, concentrates). Close to one third of NABS carried the 'Lower in Sugar' HCS tagline $(n=268,30 \%)$, followed by 'Sugar Free' $(n=52,6 \%)$ and 'No Added Sugar' ( $n=41,5 \%)$ taglines. Milk-based/iced teas were observed to have the highest count of each tagline statement.

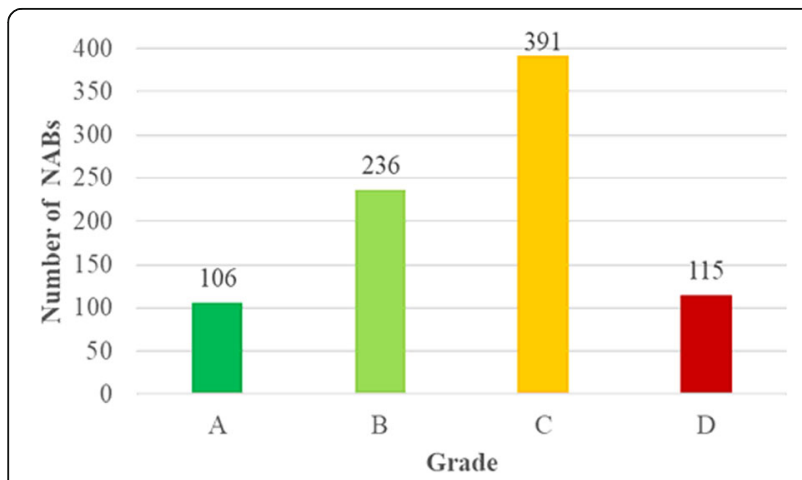

Fig. 3 Proportion of Non-Alcoholic Beverages in each Nutri-Grade $(n=848)$
Slightly more than one quarter of NABs $(n=241,27 \%)$ contain the use of sugar substitute(s) in their product formulations. The usage of sugar substitutes was found to be most popular among energy drinks $(n=24,80 \%)$, but completely absent among vitamin drink products. Instead, all vitamin drinks were all calorically sweetened $(n=11,100 \%)$. Within each of the twelve sub-categories, there is still a small proportion of beverages that are calorically sweetened with sugar. The prevalence of NABs classified as calorically sweetened beverages remains the highest at 59\% (Table 5).

Based on the four types of sugar substitutes (classified in Table 1), zero-calorie artificial sweeteners were the most commonly used ( $n=264,30 \%)$, followed by sugar alcohols $(n=63,7 \%)$, natural sweeteners $(n=55$, $6 \%)$, and lastly, caloric artificial sweeteners $(n=17$, $2 \%)$. The presence of sucralose $(n=143,16 \%)$ and acesulfame-k $(n=120,14 \%)$ were comparable in terms of its frequency and prevalence used among NABs containing zero-calorie artificial sweeteners. Both substitutes were predominantly used in carbonated drinks. Carbonated drinks also contained the most diverse range of sugar substitutes (7 different types). The next most popular alternative to zero-calorie artificial sweeteners were sugar alcohols $(n=63,7 \%)$, with sorbitol being the most utilized sugar substitute $(n=28,3 \%)$. Among the natural sweeteners used in NABs, a higher percentage of steviol glycosides $(n=$ 47, 5\%) was used as compared to monk fruit extract $(n=8,1 \%)$. Although aspartame, the only caloric artificial sweetener, was the least popular sugar substitute $(n=17,2 \%)$, it was mainly found in carbonated beverages $(n=16,7 \%)$ (Table 6). The aforementioned then gives relevance to Table 7 , presenting a combination 
Table 3 Proportion of Sub-categories of Non-Alcoholic Beverages Classified in each Nutri-Grade $(n=848)$

\begin{tabular}{|c|c|c|c|c|c|c|}
\hline \multirow{2}{*}{$\begin{array}{l}\text { Free Sugar Thresholds } \\
\text { Level (g per } 100 \mathrm{~mL} / \mathrm{g} \text { ) }\end{array}$} & \multirow[t]{2}{*}{$\mathbf{n}$} & \multicolumn{4}{|l|}{ n (\%) } & \multirow[t]{2}{*}{ Ave. Nutri-Grade } \\
\hline & & $\begin{array}{l}\text { Grade } A \\
(\leq 1 \text { and no sweetener) }\end{array}$ & $\begin{array}{l}\text { Grade } B \\
(>1 \text { to } 5)\end{array}$ & $\begin{array}{l}\text { Grade } C \\
(>5 \text { to } 10)\end{array}$ & $\begin{array}{l}\text { Grade D } \\
(>10)\end{array}$ & \\
\hline Asian/Asian-style Drinks & 118 & $4(3)$ & $13(11)$ & $97(82)$ & $4(3)$ & C \\
\hline Carbonates & 219 & $22(10)$ & $83(38)$ & $74(34)$ & $40(18)$ & C \\
\hline Coconut Water & 36 & - & $30(83)$ & $6(17)$ & - & B \\
\hline Cordials, Syrups, Concentrates & 33 & $2(6)$ & $2(6)$ & $16(49)$ & $13(39)$ & $\mathrm{D}$ \\
\hline Energy Drinks & 30 & $4(13)$ & $11(37)$ & $5(17)$ & $10(33)$ & C \\
\hline Flavoured Drinks & 40 & $4(10)$ & $6(15)$ & $10(25)$ & $20(50)$ & $C$ \\
\hline Kombucha & 18 & - & $18(100)$ & - & - & B \\
\hline Milk Based/lced Coffees & 6 & - & $1(17)$ & $5(83)$ & - & C \\
\hline Milk Based/Iced Teas & 242 & $63(26)$ & $49(20)$ & $122(50)$ & $8(3)$ & C \\
\hline RTD Vinegars & 41 & $7(17)$ & $12(29)$ & $7(17)$ & $15(37)$ & $\mathrm{D}$ \\
\hline Sports/Isotonic Drinks & 54 & - & $7(13)$ & $46(85)$ & $1(2)$ & C \\
\hline Vitamin Drinks & 11 & - & $4(36)$ & $3(27)$ & $4(36)$ & $\mathrm{D}$ \\
\hline Overall & 848 & $106(13)$ & $236(28)$ & $391(46)$ & $115(14)$ & C \\
\hline
\end{tabular}

of the total number and classification of sweeteners used across in each sub-category, where most beverages contained a maximum of two different types of sugar substitutes and classifications.

\section{Discussion}

Among the 883 unique NABs identified in this study, the majority of beverages (59\%) were calorically sweetened, $14 \%$ were unsweetened and the remaining $27 \%$ were sweetened with the use of sugar substitutes. Results from this study align with findings from other studies, indicating that SSBs make up a considerable source of calories (sugar) in the diet $[9,10,34]$. Over half of
Singaporeans' total daily sugar intake is derived from pre-packaged SSBs (64\%), according to a national nutrition survey conducted by the HPB in 2018 [9-11]. Thus, the uptake and promotion of artificial sweeteners is an opportunity for consumers to reduce their overall caloric intake from SSBs. Coupled with the introduction of Nutri-Grade, this study provides a point of discussion for future research investigating the use and uptake of sugar substitutes into the market, including new and novel forms of sweeteners such as Monk fruit [35, 36].

Carbonated drinks as a product sub-category had the most diverse use of sugar substitutes; 7 unique types as well as multiple use of different sweeteners in the same

Table 4 Proportion of Non-Alcoholic Beverages Carrying HCS and Its Accompanying Taglines $(n=883)$

\begin{tabular}{|c|c|c|c|c|c|}
\hline & \multirow[t]{2}{*}{$\mathrm{n}$} & \multicolumn{4}{|l|}{ n (\%) } \\
\hline & & Lower in Sugar & No Added Sugar & Sugar Free & No Tagline \\
\hline Asian/Asian-style Drinks & 124 & $54(44)$ & - & $1(1)$ & $69(56)$ \\
\hline Carbonates & 222 & $55(25)$ & $1(1)$ & $23(10)$ & $143(64)$ \\
\hline Coconut Water & 38 & $12(32)$ & $18(47)$ & - & $8(21)$ \\
\hline Cordials, Syrups, Concentrates & 48 & - & - & - & $48(100)$ \\
\hline Energy Drinks & 30 & - & - & - & $30(100)$ \\
\hline Flavoured Drinks & 41 & $9(22)$ & $2(5)$ & - & $30(73)$ \\
\hline Kombucha & 18 & - & - & - & $18(100)$ \\
\hline Milk Based/lced Coffees & 6 & $1(17)$ & - & - & $5(83)$ \\
\hline Milk Based/lced Teas & 249 & $89(36)$ & $20(8)$ & $23(9)$ & $117(47)$ \\
\hline RTD Vinegars & 42 & - & - & - & $42(100)$ \\
\hline Sports/Isotonic Drinks & 54 & $43(80)$ & - & $5(9)$ & $6(11)$ \\
\hline Vitamin Drinks & 11 & $5(46)$ & - & - & $6(55)$ \\
\hline Overall & 883 & $268(30)$ & $41(5)$ & $52(6)$ & $522(59)$ \\
\hline
\end{tabular}


Table 5 Frequency of Sugar Substitutes Used and Its Corresponding Classification $(n=883)$

\begin{tabular}{|c|c|c|c|c|c|c|c|}
\hline & \multirow[t]{3}{*}{$\mathbf{n}$} & \multicolumn{6}{|l|}{ n (\%) } \\
\hline & & \multicolumn{3}{|c|}{ Contain the Use of Sugar Substitute(s) } & \multicolumn{3}{|c|}{ Do Not Contain the Use of Sugar Substitute(s) } \\
\hline & & $\begin{array}{l}\text { Intensely Sweetened } \\
\text { Beverages }\end{array}$ & $\begin{array}{l}\text { Both Calorically and } \\
\text { Intensely Sweetened } \\
\text { Beverages }\end{array}$ & Total & $\begin{array}{l}\text { Unsweetened } \\
\text { Beverages }\end{array}$ & $\begin{array}{l}\text { Calorically Sweetened } \\
\text { Beverages }\end{array}$ & Total \\
\hline Asian/Asian-style Drinks & 124 & - & $27(22)$ & $27(22)$ & $7(6)$ & $90(73)$ & $97(79)$ \\
\hline Carbonates & 222 & $28(13)$ & $70(32)$ & $98(45)$ & $26(12)$ & $98(44)$ & $124(56)$ \\
\hline Coconut Water & 38 & - & $6(16)$ & $6(16)$ & $27(71)$ & $5(13)$ & $32(84)$ \\
\hline Cordials, Syrups, Concentrates & 48 & $2(4)$ & - & $2(4)$ & - & $46(96)$ & $46(96)$ \\
\hline Energy Drinks & 30 & $9(30)$ & $15(50)$ & $24(80)$ & - & $6(20)$ & $6(20)$ \\
\hline Flavoured Drinks & 41 & $3(7)$ & $8(20)$ & $11(27)$ & $2(5)$ & $28(68)$ & $30(73)$ \\
\hline Kombucha & 18 & - & $1(6)$ & $1(6)$ & - & $17(94)$ & $17(94)$ \\
\hline Milk Based/Iced Coffees & 6 & - & $2(33)$ & $2(33)$ & - & $4(67)$ & $4(67)$ \\
\hline Milk Based/Iced Teas & 249 & $2(1)$ & $48(19)$ & $50(20)$ & $52(21)$ & $147(59)$ & $199(80)$ \\
\hline RTD Vinegars & 42 & $7(17)$ & $6(14)$ & $13(31)$ & $10(24)$ & $19(45)$ & $29(69)$ \\
\hline Sports/Isotonic Drinks & 54 & $5(9)$ & $2(4)$ & $7(13)$ & - & $47(87)$ & $47(87)$ \\
\hline Vitamin Drinks & 11 & - & - & - & - & $11(100)$ & $11(100)$ \\
\hline Overall & 883 & $56(6)$ & $185(21)$ & $241(27)$ & $124(14)$ & $518(59)$ & $642(73)$ \\
\hline
\end{tabular}

* Both calorically and intensely sweetened beverages contain both added sugar and one or more sugar substitute(s)

product (Table 7). These findings are consistent with a recent study, which assessed the presence of sugar substitutes used in twelve major food and beverage subgroups across four countries [37, 38]. It was reported that Chile encompassed the highest magnitude of products containing non-nutritive sweeteners in most categories along with soft drinks/sodas dominating the total amount of non-nutritive sweeteners being used within the beverage's category [37, 38]. Similarly, the top three sugar substitutes used in carbonated drinks; sucralose, acesulfame- $K$ and aspartame, were in line with findings from a study conducted by Buffini et al., in investigating the most widely utilised and consumed sweeteners present among the Irish adult population diet [39].

Conversely, vitamin drinks did not contain any sugar substitutes, but contained the highest energy, carbohydrate, and sugar values across all twelve sub-categories. These high values are reflected in the Nutri-Grade assigned to these beverages - 'red' Grade D label for highest sugar levels (23\%). Examples of vitamin drinks include brands such as Glacéau and YOU-C1000. More often than not, the major selling point of vitamin drinks is their promotion of functional and hydration benefits associated with achieving optimal sports/athletic and health performance from the fortification of vitamins, minerals, and electrolytes [40, 41]. Thus, the replacement of natural sugars with sugar substitutes may not be a key manufacturing consideration in product development or reformulations in appealing to consumers. That said, there is still a fraction of consumers who instinctively view and associate such beverages incorrectly with healthier alternatives, which could be a cause of concern if these drinks are consumed frequently and/or in the absence of physical activity.

More than half of NABs in this study have high sugar contents and would be assigned either 'yellow' Grade Cs (46\%) or 'red' Grade Ds (14\%), paralleling an analysis conducted by HPB that found that the proportion of beverages classified as Grade C was approximately 50\% and accounted for $51 \%$ of the total sales in the current market [10-12]. As Nutri-Grade is gradually implemented, it will be worthwhile to track how the usage of both sugar and sugar substitutes in NABs may vary in the short and long-term. Such findings are reflected in other studies of countries which introduced similar nutrient labelling systems, prompting the need to undertake product reformulations to improve the overall healthfulness of food retail markets [42-45]. One such example demonstrated was the Health Star Rating (HSR) programme implemented in New Zealand [45]. Since the implementation of the HSR programme, improvements were observed in certain nutritional compositions of packaged food products particularly, energy, fibre, and sodium density [45].

Another strong example is the impact of Chile frontof-pack labelling to warn consumers about the health risks of sugar over-consumption [43, 44]. Chile became the first country to administer mandatory warning labels on the front of packs for sugar levels in food in 2016 $[43,44]$. As a result, the pressure to maintain consumer loyalty and product sales led many food companies to reformulate their products by replacing sucrose with 


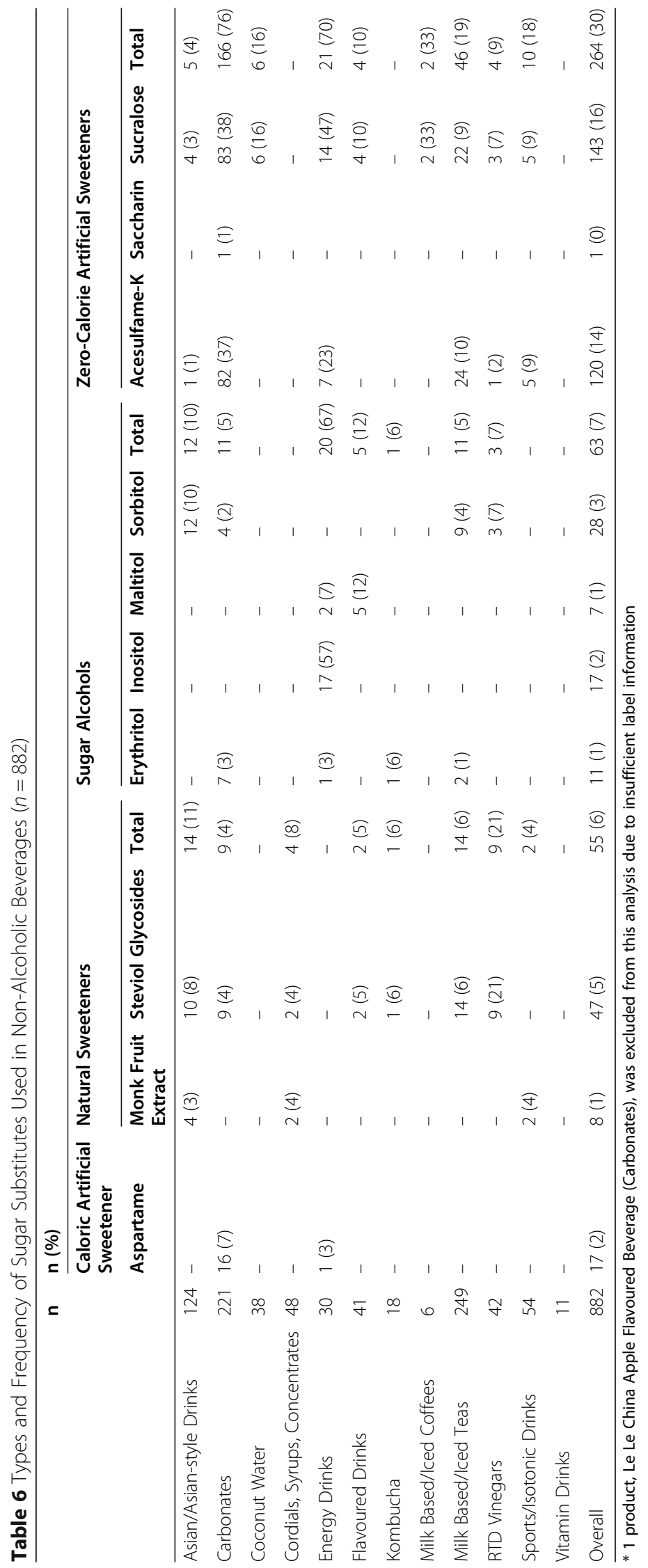


Table 7 Total Average Number and Classification of Sugar Substitutes(s) Used Across each Sub-Category $(n=883)$

\begin{tabular}{|c|c|c|c|c|c|c|c|c|c|c|c|}
\hline & \multirow[t]{3}{*}{$\mathbf{n}$} & \multicolumn{10}{|l|}{ n (\%) } \\
\hline & & \multicolumn{6}{|c|}{ Number of Sugar Substitute(s) Used } & \multicolumn{4}{|c|}{$\begin{array}{l}\text { Number of Classification of Sugar } \\
\text { Substitute(s) Used }\end{array}$} \\
\hline & & 0 & 1 & 2 & 3 & 4 & $\begin{array}{l}\text { Not Otherwise } \\
\text { Defined }\end{array}$ & $\overline{0}$ & 1 & 2 & $\begin{array}{l}\text { Not Otherwise } \\
\text { Defined }\end{array}$ \\
\hline Asian/Asian-style Drinks & 124 & $97(78)$ & $23(19)$ & $4(3)$ & - & - & - & $97(78)$ & $23(19)$ & $4(3)$ & - \\
\hline Carbonates & 222 & $124(56)$ & $5(2)$ & $79(36)$ & $13(6)$ & - & $1(1)$ & $124(56)$ & $71(32)$ & $26(12)$ & $1(1)$ \\
\hline Coconut Water & 38 & $32(84)$ & $6(16)$ & - & - & - & - & $32(84)$ & $6(16)$ & - & - \\
\hline Cordials, Syrups, Concentrates & 48 & $46(96)$ & - & $2(4)$ & - & - & - & $46(96)$ & $2(4)$ & - & - \\
\hline Energy Drinks & 30 & $6(20)$ & $13(43)$ & $7(23)$ & 1 (3) & $3(10)$ & - & $6(20)$ & $15(50)$ & $9(30)$ & - \\
\hline Flavoured Drinks & 41 & $30(73)$ & $11(27)$ & - & - & - & - & $30(73)$ & $11(27)$ & - & - \\
\hline Kombucha & 18 & $17(94)$ & - & $1(6)$ & - & - & - & $17(94)$ & - & $1(6)$ & - \\
\hline Milk Based/Iced Coffees & 6 & $4(67)$ & $2(33)$ & - & - & - & - & $4(67)$ & $2(33)$ & - & - \\
\hline Milk Based/lced Teas & 249 & $199(80)$ & $29(12)$ & $21(8)$ & - & - & - & $199(80)$ & $50(20)$ & - & - \\
\hline RTD Vinegars & 42 & $29(69)$ & $10(24)$ & $3(7)$ & - & - & - & $29(69)$ & $11(26)$ & $2(5)$ & - \\
\hline Sports/Isotonic Drinks & 54 & $47(87)$ & $2(4)$ & $5(9)$ & - & - & - & $47(87)$ & $7(13)$ & - & - \\
\hline Vitamin Drinks & 11 & $11(100)$ & - & - & - & - & - & $11(100)$ & - & - & - \\
\hline Overall & 883 & $642(73)$ & $101(11)$ & $122(14)$ & $14(2)$ & $3(0)$ & $1(0)$ & $642(73)$ & $198(22)$ & $42(5)$ & $1(0)$ \\
\hline
\end{tabular}

*Not Otherwise Defined: $(n=1)$ : Data from Le Le China Apple Flavoured Beverage (Carbonates) as types of sweeteners used were not specified on product label

non-caloric sweeteners, thereby supporting the government initiative in decreasing the average overall energy intake of consumers, and effectively demonstrating the significant downstream effects labelling initiatives can have on shifting consumer purchase behaviour [43, 44].

The similarity in background rationale and objectives of the New Zealand (NZ) and Chilean policies with Singapore's Nutri-Grade suggests that, upon implementation, the reduction in the proportion of sugar in NABs is attainable. Consequently, it is hypothesised that for future new beverage development or reformulations, there will be a shift away from added sugar in NABs towards sugar substitutes. This assists the beverage industries in leveraging off the anticipated/forecasted increased consumer demand for NABs in qualifying the desirable healthy Nutri-Grade label and/or HCS logos and its respective tagline(s) $[12,13]$. It will also be interesting to track how the new labelling is understood and perceived by consumers. Both the HCS and Nutri-Grade labelling are marketed collectively on Grades A and B beverage packaging so it will be interesting to observe which categorisation drives future consumer choice [12-15]. For instance, will consumers differentiate between a Grade A beverage that contains zero added sugar versus $1 \%$ added sugar or just equate all Grade A beverages as equivalent? Equally, is a Grade B beverage with $1 \%$ sugar but the addition of sweeteners perceived differently? [12-15]. At this stage, we cannot make any informed comment, but it is something that will be interesting to track in the future and the methodology described in this study provides a tool for us to do so.
An expansion of the usage of more sugar substitutes by formulators to ensure an A or B grading is a tangible prospective next step after the implementation of the Nutri-Grade system [46-48]. What impact this has on the diet and health outcomes of Singaporeans cannot be ascertained by this study nor is it the intention of this paper to debate the health benefits nor implications of sweeteners versus sugar, however, monitoring such trends is important. Some concerns have been raised over the use of artificial sweeteners in foods on top of the growing concerns many have with sugar [49-52]. Thus, a proper understanding and assessment of the change in trend of sweeteners and sugar use in the Singapore diet, alongside measures of population health, is important so that we can identify emerging correlations between product composition and changing dietary practices and health metrics as well as adequately assess the level of impact of any new data on the safety of sweeteners present in the Singapore diet.

We also expect to see an increase over time in the use of natural sweeteners. Interestingly, despite the fact that natural sweeteners have the health halo of being plantbased, their uptake and use so far in NABs is limited (6\%) [49]. A possible explanation for this observation could be that the process of identifying the right types and amounts of natural sweeteners to formulate the requisite sensory qualities of beverages is not a simple undertaking [52-55]. For instance, Stevia has been marketed as a promising renewable raw ingredient in the food industry for many years, but multiple studies have documented that its characteristic metallic, bitter 
aftertaste negatively influences consumer acceptance [54-56]. Another natural sweetener, monk fruit extract, is still a relatively new ingredient to the market with limited and inconclusive research examining its safety effects and sensory profile, to date as an additive [55]. While such challenges impose a hinderance, current direction shows that consumers are gravitating towards a clean, natural, and sustainable product label considering that society are becoming increasingly aware and interested in valuing their own health $[35,36]$. We are keen to see how trends in natural sweeteners grow in beverages on the Singapore market. Moving forward, these natural sweeteners provide an alternative yet viable solution for the beverage industries to stay relevant to consumer preferences whilst meeting the requirements of health-based policies such as Nutri-Grade [15].

To the best of our knowledge, the present study is the first to be conducted which identifies and examines the types and proportion of sugar and/or sugar substitutes used in NABs sold on the Singapore market and available in the diet. It serves as a 'point zero' to track and evaluate the proportion of sugars in beverages as well as the amount of average sugar being displaced by sugar substitutes over time due to the upcoming implementation of the Nutri-Grade labelling system for all branded retail products.

It is acknowledged that the approach used in this study does not take into account sugar and/or sugar substitutes present in freshly prepared beverages sold over the counter such as Starbucks ${ }^{\mathrm{Tm}}$ and McDonald's ${ }^{\circ}$ [11]. However, it was not the primary aim of the study to look at sugar intake per se, but rather, to examine pre-packaged beverages where labelling is mandatory for sugar. Over-the-counter products sold in Singapore do not require nutrient labelling nor any ingredient composition listing. In order to undertake a dietary exposure study of sugar and sweetener intake in Singapore, we intend to expand our categories to other beverages available through retail stores e.g., flavoured milk and milk alternatives, as well as investigate how to apply a similar data collection methodology to over-the-counter products. In addition, we are looking to expand our data collection across all product categories as part of the development of a national branded food database for Singapore and to investigate other labelling requirements. We view the collection of such market product data as an important tool to understand the dietary composition of Singaporeans, guide policy decisions and investigate topical research questions such as the one addressed in this paper.

\section{Conclusion}

With continuous efforts by the government in promoting public health nutrition, it is expected that there will be a greater usage of sugar substitutes among NABs in response to the upcoming implementation of Nutri-Grade and ever-fluctuating consumers' demands. Going forward, what effect(s) it has on the beverage composition will need to be further assessed. The comprehensive baseline data collected in this study provides a solid foundation on which to assess future changes in product formulae and the impact of the Nutri-Grade system on the composition of beverages available on the Singapore market and in the Singapore diet.

\section{Abbreviations}

HCS: Healthier Choice Symbol; HPB: Health Promotion Board; NABs: NonAlcoholic Beverages; NIP: Nutritional Information Panel; SSBs: Sugar Sweetened Beverages; T2DM: Type 2 Diabetes Mellitus

\section{Supplementary Information}

The online version contains supplementary material available at https://doi. org/10.1186/s12889-021-11924-0.

Additional file 1: Appendix 1. Category Definition - Non-Alcoholic Beverages (NABs).

\section{Acknowledgements}

Not Applicable.

\section{Authors' contributions}

Writing-original draft preparation, S.C., R.T. and B.P.C.S.; conceptualization, data curation, supervision, B.P.C.S. and R.T.; formal analysis, investigation, S.C.; data collection methodology, software, writing - review and editing; X.C., K.A., P.G.B. and T.P. All authors have read and agreed to the published version of the manuscript.

\section{Funding}

This study was funded under the Singapore-Australia Bilateral Program on Innovations in Food for Precision Health 2019. BPC Smith was supported by a National Research Foundation Singapore Whitespace grant (grant no. W20W3D0002) and Health and Biomedical Sciences Industry Alignment Fund Pre-positioning grant (H1801a0-014) administered by the Agency for Science, Technology \& Research.

\section{Availability of data and materials}

This study was funded under the Singapore-Australia Bilateral Program on Innovations in Food for Precision Health 2019. BPC Smith was supported by a National Research Foundation Singapore Whitespace grant (grant no. W20W3D0002) and Health and Biomedical Sciences Industry Alignment Fund Pre-positioning grant (H1801a0-014) administered by the Agency for Science, Technology \& Research.

\section{Declarations}

Ethics approval and consent to participate Not Applicable.

\section{Consent for publication}

Not Applicable (The data supporting the findings of this study are held by CSIRO and A*STAR and can potentially be made available upon request.)

\section{Competing interests}

The authors declare no conflict of interest (no potential competing interest was reported by the authors). The funders had no role in the design of the study; in the collection, analyses, or interpretation of data; in the writing of the manuscript, or in the decision to publish the results. 


\section{Author details}

${ }^{1}$ Singapore Institute of Food and Biotechnology Innovation \& Innovations in Food \& Chemical Safety Programme, Agency for Science, Technology and Research, Singapore 138671, Singapore. ${ }^{2}$ Health \& Biosecurity, The Commonwealth Scientific and Industrial Research Organisation, Canberra, ACT 2601, Australia. ${ }^{3}$ National Heart Foundation Australia, Docklands, VIC 3008, Australia. ${ }^{4}$ Future Ready Food Safety Hub, C/O School of Chemical \& Biomedical Engineering, Nanyang Technical University, Singapore 637459, Singapore.

\section{Received: 16 April 2021 Accepted: 5 October 2021} Published online: 16 October 2021

\section{References}

1. Wang M, Yu M, Fang L, Hu RY. Association between sugar-sweetened beverages and type 2 diabetes: a meta-analysis. J Diabetes Invest. 2015;6(3): 360-6. https://doi.org/10.1111/jdi.12309.

2. Malik VS, Popkin BM, Bray GA, Després JP, Willett WC, Hu FB. Sugarsweetened beverages and risk of metabolic syndrome and type 2 diabetes: a meta-analysis. Diabetes Care. 2010;33(11):2477-83. https://doi.org/10.2337/ dc10-1079.

3. Schulze MB, Manson JE, Ludwig DS, Colditz GA, Stampfer MJ, Willett WC, et al. Sugar-sweetened beverages, weight gain, and incidence of type 2 diabetes in young and middle-aged women. J Am Med Assoc (JAMA). 2004; 292(8):927-34. https://doi.org/10.1001/jama.292.8.927.

4. Brownell KD, Farley T, Willett WC, Popkin BM, Chaloupka FJ, Thompson JW, et al. The public health and economic benefits of taxing sugar-sweetened beverages. N Engl J Med. 2009;361(16):1599-605. https://doi.org/10.1056/ NEJMhpr0905723.

5. Luger M, Lafontan M, Bes-Rastrollo M, Winzer E, Yumuk V, Farpour-Lambert N. Sugar-sweetened beverages and weight gain in children and adults: a systematic review from 2013 to 2015 and a comparison with previous studies. Obes Facts. 2017;10(6):674-93. https://doi.org/10.1159/000484566.

6. Hu FB. Resolved: there is sufficient scientific evidence that decreasing sugarsweetened beverage consumption will reduce the prevalence of obesity and obesity-related diseases. Obes Rev. 2013;14(8):606-19. https://doi.org/1 0.1111/obr.12040

7. Gui ZH, Zhu YN, Cai L, Sun FH, Ma YH, Jing J, et al. Sugar-sweetened beverage consumption and risks of obesity and hypertension in Chinese children and adolescents: a national cross-sectional analysis. Nutrients. 2017; 9(12):1302. https://doi.org/10.3390/nu9121302.

8. Papier K, D'este C, Bain C, Banwell C, Seubsman S, Sleigh A, et al. Consumption of sugar-sweetened beverages and type 2 diabetes incidence in Thai adults: results from an 8-year prospective study. Nutr Diabetes. 2017; 7(6):e283. https://doi.org/10.1038/nutd.2017.27.

9. Health Hub Health Promotion Board (HPB). National Nutrition Survey 2018 Shows Gradual Improvements in Singaporeans' Dietary Habits 2018. https:// www.hpb.gov.sg/article/national-nutrition-survey-2018-shows-gradualimprovements-in-singaporeans-dietary-habits. Accessed 11 Jan 2021.

10. Ministry of Health $(\mathrm{MOH})$. Summary of Qualitative Findings on Nutrition Label Designs for Beverages. 2020. https://www.moh.gov.sg/docs/libra riesprovider5/default-document-library/summary-of-findings-from-qualita tive-study-on-labels-for-beverages.pdf. Accessed 02 Feb 2021.

11. Ministry of Health $(\mathrm{MOH})$. Report on Findings from the Public Consultation on Possible Measures for Pre-Packaged Sugar-Sweetened Beverages. 2019. https://www.moh.gov.sg/docs/librariesprovider5/defaultdocument-library/annex-adc590d389f7f49af96c536d1ed62acb1.pdf. Accessed 02 Feb 2021.

12. Ministry of Health (MOH). Introduce Measures to Reduce Sugar Intake from Pre-Packaged Sugar-Sweetened Beverages. 2019. https://www.moh.gov.sg/ docs/librariesprovider5/default-document-library/press-release\%2D\%2D-ssbmeasuresd949138164cd4d7295c78c00263f7b18.pdf. Accessed 11 Jan 2021.

13. Ministry of Health (MOH). Make a Healthier Choice Today! 2021. https:// www.healthhub.sg/live-healthy/211/make_healthier_choice. Accessed 02 Feb 2021.

14. $\mathrm{MOH}$. Report on Findings from the Public Consultation on Possible Measures for Pre-packaged Sugar-sweetened Beverages. 2019. https://www. moh.gov.sg/docs/librariesprovider5/default-document-library/annex-a dc590d389f7f49af96c536d1ed62acb1.pdf. Accessed 24 Aug 2021.

15. Singapore Food Agency (SFS). Consultation on Draft Food (Amendment) Regulations 2021: Labelling and advertising requirements for "Nutri-Grade beverages" sold in Singapore. 2021. https://www.sfa.gov.sg/docs/defaultsource/legislation/sale-of-food-act/consultation-on-labelling-and-advertisingrequirements-for-nutri-grade-beverages-(updated).pdf. Accessed 24 Aug 2021.

16. Tandel KR. Sugar substitutes: health controversy over perceived benefits. J Pharmacol Pharmacother. 2011;2(4):236-43. https://doi.org/10.4103/0976500X.85936.

17. Purohit $\mathrm{V}$, Mishra $\mathrm{S}$. The truth about artificial sweeteners-are they good for diabetics? Indian Heart J. 2018;70(1):197-9. https://doi.org/10.1016/j.ihj.2018. 01.020 .

18. Harvard School of Public Health. The Nutrition Source - Low-Calorie Sweeteners. 2021. https://www.hsph.harvard.edu/nutritionsource/healthydrinks/artificial-sweeteners/. Accessed 11 Aug 2021.

19. Thomas L. Sugar substitutes: types and uses. 2019. https://www.newsmedical.net/health/Sugar-Substitutes-Types-and-Uses.aspx. Accessed 11 Jan 2021.

20. Joint FAO/WHO Codex Alimentarius Commission. Class Names and the International Numbering System for Food Additives. CXG 36-1989; 1985. http://www.fao.org/fao-who-codexalimentarius/sh-proxy/en/? Ink=1\&url= https\%253A\%252F\%252Fworkspace.fao.org\%252Fsites\%252Fcodex\%252FSta ndards\%252FCXG\%2B36-1989\%252FCXG_036e.pdf. Accessed 11 Jan 2021.

21. The Food and Drug Administration (FDA). Additional Information about High-Intensity Sweeteners Permitted for Use in Food in the United States. 2021. https://www.fda.gov/food/food-additives-petitions/additional-informa tion-about-high-intensity-sweeteners-permitted-use-food-united-sta tes\#nutritive. Accessed 11 Aug 2021.

22. Diabetes.co.uk. Sugar Alcohols. 2019. https://www.diabetes.co.uk/ sweeteners/sugar-alcohols.html. Accessed 11 Aug 2021.

23. Food Standards Australia New Zealand (FSANZ). Intense Sweeteners. 2019. https://www.foodstandards.gov.au/consumer/additives/Pages/Sweeteners.a spx. Accessed 02 Feb 2021.

24. Pearlman M, Obert J, Casey L. The association between artificial sweeteners and obesity. Curr Gastroenterol Rep. 2017;19(12):64. https://doi.org/10.1007/ s11894-017-0602-9.

25. Meni AC, Swithers SE, Rother KI. Positive association between artificially sweetened beverage consumption and incidence of diabetes. Diabetologia. 2015:58(10):2455-6. https://doi.org/10.1007/s00125-015-3694-5.

26. Ruanpeng D, Thongprayoon C, Cheungpasitporn W, Harindhanavudhi T. Sugar and artificially sweetened beverages linked to obesity: a systematic review and meta-analysis. QJM. 2017;110(8):513-20. https://doi.org/10.1093/ qjimed/hcx068.

27. Peters JC, Wyatt HR, Foster GD, Pan Z, Wojtanowski AC, Vander Veur SS, et al. The effects of water and non-nutritive sweetened beverages on weight loss during a 12-week weight loss treatment program. Obesity. 2014;22(6):1415-21. https://doi.org/10.1002/oby.20737.

28. Sørensen LB, Vasilaras TH, Astrup A, Raben A. Sucrose compared with artificial sweeteners: a clinical intervention study of effects on energy intake, appetite, and energy expenditure after $10 \mathrm{wk}$ of supplementation in overweight subjects. Am J Clin Nutr. 2014;100(1):36-45. https://doi.org/10.3 945/ajcn.113.081554.

29. Raben A, Vasilaras TH, Møller AC, Astrup A. Sucrose compared with artificial sweeteners: different effects on ad libitum food intake and body weight after 10 wk of supplementation in overweight subjects. Am J Clin Nutr. 2002;76(4):721-9. https://doi.org/10.1093/ajcn/76.4.721.

30. Tordoff MG, Alleva AM. Effect of drinking soda sweetened with aspartame or high-fructose corn syrup on food intake and body weight. Am J Clin Nutr. 1990;51(6):963-9. https://doi.org/10.1093/ajcn/51.6.963.

31. Wee M, Tan V, Forde C. A comparison of psychophysical dose-response behaviour across 16 sweeteners. Nutrients. 2018;10(11):1632. https://doi. org/10.3390/nu10111632.

32. Asioli D, Aschemann-Witzel J, Caputo V, Vecchio R, Annunziata A, Næs T, et al. Making sense of the "clean label" trends: a review of consumer food choice behavior and discussion of industry implications. Food Res Int. 2017; 99(Pt 1):58-71. https://doi.org/10.1016/j.foodres.2017.07.022.

33. Saraiva A, Carrascosa C, Raheem D, Ramos F, Raposo A. Natural sweeteners: the relevance of food naturalness for consumers, food security aspects, sustainability and health impacts. Int J Environ Res Public Health. 2020; 17(17):6285. https://doi.org/10.3390/ijerph17176285.

34. Commonwealth Scientific and Industrial Research Organisation (CSIRO). FoodTrack ${ }^{\text {TM }}$ Food \& Nutrient Database. 2021. https://www.csiro.au/en/Resea rch/Health/Nutrition-science/Nutrition-databases/FoodTrack. Accessed 11 Jan 2021. 
35. Sylvetsky AC, Rother Kl. Trends in the consumption of low-calorie sweeteners. Physiol Behav. 2016;164(Pt B):446-50. https://doi.org/10.1016/j.physbeh.2016.03.030

36. Drewnowski A, Rehm CD. Socio-demographic correlates and trends in lowcalorie sweetener use among adults in the United States from 1999 to 2008. Eur J Clin Nutr. 2015;69(9):1035-41. https://doi.org/10.1038/ejcn.2015.38.

37. Bleich SN, Wang YC, Wang Y, Gortmaker SL. Increasing consumption of sugar-sweetened beverages among US adults: 1988-1994 to 1999-2004. Am J Clin Nutr. 2009;89(1):372-81. https://doi.org/10.3945/ajcn.2008.26883.

38. Backholer K, Martin J. Sugar-sweetened beverage tax: the inconvenient truths. Public Health Nutr. 2017;20(18):3225-7. https://doi.org/10.1017/S13 68980017003330

39. Buffini M, Goscinny S, Van Loco J, Nugent AP, Walton J, Flynn A, et al. Dietary intakes of six intense sweeteners by lrish adults. Food Addit Contam Part A. 2018;35(3):425-38. https://doi.org/10.1080/19440049.2017.1411619.

40. Sichert-Hellert W, Wenz G, Kersting M. Vitamin intakes from supplements and fortified food in German children and adolescents: results from the DONALD study. J Nutr. 2006;136(5):1329-33. https:/doi.org/10.1093/jn/136.5.1329.

41. Kang AR, Park SH, Woo JW, Hong DJ, Kim KR, Sung CY, et al. Are vitamin beverages good for dental health? J Dental Hyg Sci. 2020;20(1):9-15. https://doi.org/10.17135/jdhs.2020.20.1.9.

42. Dunford EK, Taillie LS, Miles DR, Eyles H, Tolentino-Mayo L, Ng SW. Nonnutritive sweeteners in the packaged food supply —an assessment across 4 countries. Nutrients. 2018;10(2):257. https://doi.org/10.3390/nu10020257.

43. Sambra V, López-Arana S, Cáceres P, Abrigo K, Collinao J, Espinoza A, et al. Overuse of non-caloric sweeteners in foods and beverages in Chile: a threat to Consumers' free choice? Front Nutr. 2020;17(7):68. https://doi.org/10.33 89/fnut.2020.00068.

44. Reyes M, Smith Taillie L, Popkin B, Kanter R, Vandevijvere S, Corvalán C. Changes in the amount of nutrient of packaged foods and beverages after the initial implementation of the Chilean law of food labelling and advertising: a nonexperimental prospective study. Public Library Sci (PLoS) Med. 2020;28(17):7e1003220. https://doi.org/10.1371/journal.pmed.1003220

45. Mhurchu CN, Eyles $\mathrm{H}$, Choi YH. Effects of a voluntary front-of-pack nutrition labelling system on packaged food reformulation: the health star rating system in New Zealand. Nutrients. 2017;9(8):918. https://doi.org/10.3390/nu9080918.

46. Bablani L, Mhurchu CN, Neal B, Skeels CL, Staub KE, et al. The impact of voluntary front-of-pack nutrition labelling on packaged food reformulation: a difference-indifferences analysis of the Australasian health star rating scheme. PLoS Med. 2020; 17(11):e1003427. https://doi.org/10.1371/journal.pmed.1003427.

47. van der Bend DLM, Jansen $L$, van der Velde G, Blok $V$. The influence of a front-of-pack nutrition label on product reformulation: a ten-year evaluation of the Dutch choices programme. Food Chem X. 2020;6:100086. https://doi. org/10.1016/j.fochx.2020.100086.

48. Jones A, Neal B, Reeve B, Mhurchu CN, Thow AM. British Medical Journal (BMJ) Glob Health. 2019;4:e001882. https://doi.org/10.1136/bmjgh-2019-001882.

49. Ministry of Health $(\mathrm{MOH})$. Supporting Singaporeans to Care for their Health and Wellbeing. 2020. https://www.moh.gov.sg/docs/librariesprovider5/defa ult-document-library/cos-2020-supporting-singaporeans-to-care-for-theirown-health-factsheet-(ssb-and-water).pdf. Accessed 02 Feb 2021.

50. Khan SA. Artificial sweeteners: safe or unsafe? J Pakistan Med Assoc (JPMA). 2015;65(2):225-7.

51. Balachandran K. Natural sweeteners. J Soc Health Diabetes. 2018;6(1):8. https://doi.org/10.4103/JSHD.JSHD_20_17.

52. Parker MN, Lopetcharat $K$, Drake MA. Consumer acceptance of natural sweeteners in protein beverages. J Dairy Sci. 2018;101(10):8875-89. https:/ doi.org/10.3168/jds.2018-14707.

53. Goraya RK, Bajwa U. The sweetness technology of sugar substituted low calorie beverages. Food Nutr J. 2016.

54. Shinde MR, Winnier J. Effects of stevia and xylitol chewing gums on salivary flow rate, pH, and taste acceptance. J Dental Res Rev. 2020;7(2):50.

55. Suri S, Kathuria D, Mishra A, Sharma R. Phytochemical composition and pharmacological impact of natural non-calorie sweetener-monk fruit (Siraitia grosvenorii): a review. Nutr Food Sci. 2020;51(6):897-910. https://doi.org/1 0.1108/NFS-09-2020-0350.

56. Edwards $\mathrm{CH}$, Rossi $\mathrm{M}$, Corpe $\mathrm{CP}$, Butterworth PJ, Ellis PR. The role of sugars and sweeteners in food, diet and health: alternatives for the future. Trends Food Sci Technol. 2016;56:158-66. https://doi.org/10.1016/j.tifs.2016.07.008.

\section{Publisher's Note}

Springer Nature remains neutral with regard to jurisdictional claims in published maps and institutional affiliations.

\section{Ready to submit your research? Choose BMC and benefit from:}

- fast, convenient online submission

- thorough peer review by experienced researchers in your field

- rapid publication on acceptance

- support for research data, including large and complex data types

- gold Open Access which fosters wider collaboration and increased citations

- maximum visibility for your research: over $100 \mathrm{M}$ website views per year

At BMC, research is always in progress.

Learn more biomedcentral.com/submissions 